\title{
The metabolic and hormonal effects of continuous subcutaneous insulin infusion therapy in diabetic children
}

\author{
G.Soltész, D.Molnár, T. Decsi, A.Hamar and L. Klujber \\ Department of Paediatrics, University of Pécs, Hungary
}

\begin{abstract}
Summary. To find out whether the concurrent metabolic and hormonal abnormalities are corrected when normoglycaemia is achieved, two groups of diabetic children (newly-diagnosed and chronically-treated) were treated with insulin pumps. Fasting levels of metabolites, lipids and hormones were measured before and after 8 to 10 days of pump treatment and the immediate postprandial hormonal and metabolic changes after a test-meal were also measured. Restoration of normoglycaemia was accompanied by correction of multiple metabolic abnormalities including the normalisation of fasting plasma free insulin, growth hormone, free fatty acid, triglyceride and total cholesterol levels. Plasma glucagon, however, decreased below normal, and significant hypoketonaemia developed in newly-diagnosed diabetic children. The fall in (VLDL + LDL)-cholesterol levels was accompanied by a substantial increase in $\mathrm{HDL}_{2}$-cholesterol concentration in newly-diagnosed diabetic children, whereas pump-
\end{abstract}

treatment resulted in a decrease of the $\mathrm{HDL}_{3}$-cholesterol subfraction in chronically-treated diabetic children. The postprandial blood glucose and free insulin profiles were similar to that of control subjects, but there was an "abnormal" postmeal fall in plasma glucagon and free fatty acid levels. These changes together with the fasting hypoglucagonaemia and hypoketonaemia indirectly suggest that optimal glycaemic control is only achievable at the expense of "increased insulin action" despite the failure to detect peripheral hyperinsulinaemia. Furthermore, the restoration of normoglycaemia and the simultaneous normalisation of the metabolic and endocrine milieu is not entirely possible with this mode of therapy.

Key words: Insulin pump therapy, metabolites, hormones, lipids.
Although continuous subcutaneous insulin infusion (CSII) therapy has become an established form of treatment in a selected group of adult diabetic patients there are only a few reports on their use in diabetic children [1-4]. Furthermore, all these studies concentrated on the short- and long-term improvement in glycaemic control in diabetic children; the effect of CSII on the concurrent hormonal and metabolic abnormalities has not been investigated. The present study was designed firstly to find out whether the short-term ( 8 to 10 days) normalisation of hyperglycaemia with CSII will also result in the correction of the fasting levels of metabolites and hormones in diabetic children; and secondly, to describe the immediate $(3 \mathrm{~h})$ postprandial metabolic and endocrine changes after "synchronized" insulin bolus and a standardised test-meal. Finally, since acute hyperglycaemic decompensation caused by accidental stoppage of CSII (e.g. needle displacement) is a relatively common complication of this mode of therapy, we have also tried to evaluate this hazard by deliberate interruption of CSII for $5 \mathrm{~h}$.

\section{Subjects and methods}

Two groups of diabetic children were studied (Table 1). Treatment in ten newly-diagnosed diabetic children was started with CSII immediately after admission (Group 1). Six conventionally-treated C-peptide negative diabetic children also started CSII (Group 2) following hospitalisation for gross glucosuria. No medication except insulin was given and informed consent was obtained from the parents of the diabetic children as well as from those of the control subjects.

The pump used was the Graseby Dynamics Syringe DriverType MS 26 model (Cambridge, UK) which delivers a fixed basal

Table 1. Clinical data of diabetic children (mean \pm SE)

\begin{tabular}{lccl}
\hline & Group 1 & Group 2 & $\begin{array}{l}\text { Control } \\
\text { subjects }\end{array}$ \\
\hline Age (years) & $10.0 \pm 1.2$ & $14.0 \pm 1.4$ & $11.3 \pm 0.3$ \\
Male/Female & $4 / 6$ & $3 / 3$ & $33 / 22$ \\
Weight (kg) & $38.8 \pm 5.1$ & $50.2 \pm 4.8$ & $38.2 \pm 2.9$ \\
Tanner stage & I-II & II-III & I-II \\
$\begin{array}{l}\text { Duration of } \\
\text { diabetes (years) }\end{array}$ & 0 & $5.7 \pm 1.1$ & - \\
Initial HbA & & & \\
Number & $14.8 \pm 0.5$ & $12.2 \pm 0.6$ & $7.1 \pm 0.3$ \\
\hline
\end{tabular}


rate of short acting insulin (Novo Actrapid MD, Bagsvaerd, Denmark) and a variable boost of insulin is given manually $30 \mathrm{~min}$ before the main meals.

Starting total daily insulin dose was $1.5 \mathrm{U} / \mathrm{kg}$ in Group 1 and $1.3 \pm 0.3 \mathrm{U} / \mathrm{kg}$ in Group 2, the latter was equivalent to the insulin dose while on conventional therapy. Dose adjustments were made on the basis of frequent capillary blood glucose monitoring (eight times per day) and mean daily insulin-requirements after 8 to 10 days were $1.41 \pm 0.01 \mathrm{U} / \mathrm{kg}$ and $1.22 \pm 0.01 \mathrm{U} / \mathrm{kg}$ in Groups 1 and 2 , respectively. Forty-five percent of the total daily dose was given as the basal rate; the remaining 55 percent was subdivided according to the meals. All children continued to eat their previous diet while on CSII.

Fasting blood samples were taken before and after 8 to 10 days on CSII treatment and after 7 days of normoglycaemia (mean daily blood glucose was $5.7 \pm 0.03 \mathrm{mmol} / 1$ and $6.4 \pm 0.04 \mathrm{mmol} / 1$ in Groups 1 and 2, respectively; calculated on the basis of 8 daily capillary blood glucose measurements). Fasting blood samples were also drawn in 55 healthy children, 9 of whom also participated in the second part of the study.

Blood samples were collected into chilled glass tubes containing $2 \mathrm{mg}$ EDTA $/ \mathrm{ml}$ blood for free fatty acid, triglyceride, cholesterol, HDL-cholesterol, C-peptide, insulin and beta-hydroxybutyrate determination. Tubes for glucagon determination contained $1000 \mathrm{~K}$.I.U. Trasylol and $2 \mathrm{mg}$ EDTA per each $\mathrm{ml}$ of blood. The samples were centrifuged immediately at $4^{\circ} \mathrm{C}$ and plasma was stored at $-20^{\circ} \mathrm{C}$ until the assays. Plasma samples were thawed only once.

In the second part of the study, all groups of children underwent a 2-day experimental protocol:

Day 1. Thirty minutes following the insulin bolus $(0.19 \pm 0.03 \mathrm{U} / \mathrm{kg}$ body weight) a standardised breakfast of identical macronutrient

Table 2. Macronutrient composition of test-meal (mean $\pm \mathrm{SE}$ )

\begin{tabular}{lllll}
\hline & $\begin{array}{l}\text { Energy } \\
\text { (KJ/fat-free } \\
\text { body mass kg) }\end{array}$ & $\begin{array}{l}\text { Carbo- } \\
\text { hydrate } \\
(\%)\end{array}$ & $\begin{array}{l}\text { Fat } \\
(\%)\end{array}$ & $\begin{array}{l}\text { Protein } \\
(\%)\end{array}$ \\
\hline Control children & $60.3 \pm 2.3$ & 38 & 38 & 24 \\
Diabetic children & $57.4 \pm 1.2$ & 39 & 37 & 24 \\
\hline
\end{tabular}

composition (Table 2) was consumed and blood glucose, metabolites and hormones were measured in the fasting state and $30,60,90,120$ and $180 \mathrm{~min}$ after breakfast. No insulin was given to the control subjects. Beta-hydroxybutyrate levels were measured only at 0 and $180 \mathrm{~min}$ in all groups and glucagon levels are available only for 0 and $180 \mathrm{~min}$ for control subjects. The children remained recumbent for $3 \mathrm{~h}$ during which period metabolic rate was also measured.

Day 2. CSII was deliberately interrupted for $5 \mathrm{~h}$ (the needle remaining in situ) and the children remained resting and fasting. Their capillary blood glucose concentration was followed and urine samples were tested for ketones hourly.

Blood glucose was measured by the glucose oxidase method [5]. Triglyceride and cholesterol were determined enzymatically with the help of a Boehringer Mannheim, Germany kit. The method of Laurell and Tibbling [6] was used to measure plasma free fatty acid concentration. Beta-hydroxybutyrate was measured enzymatically [7]. HDL-cholesterol and its subfractions were measured with the precipitation method of Steele et al. [8] and Kahn et al. [9]. VLDL and LDL-cholesterol concentrations were obtained by subtracting HDLcholesterol from total cholesterol. Stable $\mathrm{HbA}_{1}$ was measured by chromatographic method [10]. Commercially available Biodata-Serono Kits were used for the determination of C-peptide (code 10282), glucagon (code 10904), growth hormone (code 10703) and insulin (code 1624). Free insulin in the plasma of insulin-treated diabetic children was determined also with the Biodata-Serono kit after extraction with polyethylene glycol [11]. The extraction was made immediately after the separation of the plasma. The methods of Brook [12] and Durnin and Rahman [13] were used to determine body density and fat-free body mass for the standardisation of test meal.

\section{Statistical analysis}

The data were analysed by Student's t-test and by paired Student's ttest when applicable.

\section{Results}

Fasting blood glucose, hormone, metabolite and lipid levels before and after 8 to 10 days of CSII treatment

Table 3. Fasting levels of hormones, lipids and metabolites in control and diabetic children (mean $\pm \mathrm{SE}$ )

\begin{tabular}{|c|c|c|c|c|c|c|c|}
\hline & \multicolumn{3}{|c|}{ Newly-diagnosed $(n=10)$} & \multirow[t]{2}{*}{$p<$} & \multicolumn{2}{|c|}{ Chronically-treated $(n=6)$} & \multirow[t]{2}{*}{$p<$} \\
\hline & $\begin{array}{l}\text { Control } \\
\text { subjects } \\
(n=55)\end{array}$ & $\begin{array}{l}\text { Pre- } \\
\text { treatment }\end{array}$ & $\begin{array}{l}\text { On } \\
\text { pump }\end{array}$ & & $\begin{array}{l}\text { Conventional } \\
\text { treatment }\end{array}$ & $\begin{array}{l}\text { On } \\
\text { pump }\end{array}$ & \\
\hline Blood glucose $(\mathrm{mmol} / \mathrm{l})$ & $4.3 \pm 0.3$ & $16.2 \pm 1.8^{\mathrm{c}}$ & $4.3 \pm 0.5$ & 0.001 & $15.6 \pm 1.2^{\mathrm{c}}$ & $4.4 \pm 0.4$ & 0.001 \\
\hline${ }^{1} \mathrm{IRI}(\mathrm{pmol} / 1)$ & $59.6 \pm 9.2$ & $18.1 \pm 1.6^{\mathrm{c}}$ & $92.1 \pm 21.0$ & 0.01 & $65.8 \pm 12.9$ & $70.5 \pm 23.6$ & NS \\
\hline Glucagon $(\mathrm{pmol} / \mathrm{l})$ & $43.2 \pm 10.7$ & $53.8 \pm 10.9$ & $16.7 \pm 3.8^{\mathrm{a}}$ & 0.01 & $27.2 \pm 5.2$ & $13.9 \pm 2.8^{\mathrm{a}}$ & 0.05 \\
\hline IRI/Glucagon & $1.5 \pm 0.4$ & $0.4 \pm 0.09^{\mathrm{a}}$ & $6.5 \pm 1.9^{\mathrm{a}}$ & 0.01 & $2.9 \pm 0.58$ & $6.2 \pm 2.5$ & NS \\
\hline $\mathrm{GH}(\mathrm{pmol} / \mathrm{l})$ & $241 \pm 40.8$ & $420 \pm 45.1$ & $167 \pm 45$ & 0.005 & $327.8 \pm 79.3$ & $159 \pm 39$ & NS \\
\hline $\mathrm{FFA}(\mathrm{mmol} / \mathrm{l})$ & $0.5 \pm 0.12$ & $1.2 \pm 0.15^{\mathrm{c}}$ & $0.4 \pm 0.16$ & 0.005 & $0.55 \pm 0.05$ & $0.48 \pm 0.2$ & NS \\
\hline $\begin{array}{l}\text { Beta-hydroxybutyrate } \\
(\mathrm{mmol} / \mathrm{l})\end{array}$ & $0.11 \pm 0.003$ & $2.55 \pm 1.0^{\mathrm{a}}$ & $0.07 \pm 0.01^{c}$ & 0.05 & $0.5 \pm 0.17$ & $0.18 \pm 0.08$ & NS \\
\hline Triglyceride $(\mathrm{mmol} / \mathrm{l})$ & $1.1 \pm 0.08$ & $1.92 \pm 0.22^{b}$ & $0.92 \pm 0.07$ & 0.005 & $1.5 \pm 0.3$ & $0.93 \pm 0.07$ & NS \\
\hline Cholesterol $(\mathrm{mmol} / \mathrm{l})$ & $3.8 \pm 0.12$ & $6.02 \pm 0.24$ & $4.7 \pm 0.46$ & 0.05 & $4.7 \pm 0.23^{b}$ & $3.8 \pm 0.2$ & NS \\
\hline $\begin{array}{l}\text { VLDL + LDL-cholesterol } \\
(\mathrm{mmol} / \mathrm{l})\end{array}$ & $2.5 \pm 0.14$ & $4.66 \pm 0.27^{\mathrm{c}}$ & $2.8 \pm 0.42$ & 0.005 & $3.1 \pm 0.26$ & $2.3 \pm 0.4$ & NS \\
\hline HDL-cholesterol (mmol/1) & $1.3 \pm 0.07$ & $1.1 \pm 0.09$ & $1.91 \pm 0.16^{\mathrm{c}}$ & 0.005 & $1.69 \pm 0.14^{\mathrm{a}}$ & $1.63 \pm 0.12^{\mathrm{a}}$ & 0.05 \\
\hline $\mathrm{HDL}_{2}$-cholesterol $(\mathrm{mmol} / \mathrm{l})$ & $0.57 \pm 0.03$ & $0.34 \pm 0.09^{\mathrm{a}}$ & $1.06 \pm 0.22^{\mathrm{a}}$ & 0.05 & $0.6 \pm 0.07$ & $0.80 \pm 0.1$ & NS \\
\hline $\mathrm{HDL}_{3}$-cholesterol $(\mathrm{mmol} / \mathrm{l})$ & $0.81 \pm 0.04$ & $0.76 \pm 0.09$ & $0.84 \pm 0.05$ & NS & $1.1 \pm 0.08^{b}$ & $0.83 \pm 0.07$ & 0.05 \\
\hline $\mathrm{HDL}_{2}$-chol/ $/ \mathrm{HDL}_{3}$-chol & $0.78 \pm 0.05$ & $0.46 \pm 0.08^{\mathrm{b}}$ & $1.26 \pm 0.27$ & 0.01 & $0.55 \pm 0.06^{\mathrm{b}}$ & $0.87 \pm 0.27$ & NS \\
\hline
\end{tabular}

$p$ values - pre-treatment and conventional treatment vs on pump

${ }^{\mathrm{a}} p<0.05^{\mathrm{b}} p<0.01{ }^{\mathrm{c}} p<0.001$ - control subjects vs diabetic patients

1 Free IRI in diabetic children 
are shown in Table 3. Both groups of diabetic children had high fasting blood glucose concentrations, which were normalised during CSII in both groups. None of the patients had severe hypoglycaemia during the short-term pump treatment.

Newly-diagnosed diabetic children had low free insulin, $\mathrm{HDL}_{2}$-cholesterol levels, IRI/glucagon and $\mathrm{HDL}_{2} / \mathrm{HDL}_{3}$-cholesterol ratios and elevated growth hormone, free fatty acid, beta-hydroxybutyrate, triglyceride, cholesterol and (VLDL $+\mathrm{LDL}$ )-cholesterol concentrations before CSII therapy. Pump treatment caused significant changes resulting in the normalisation of the plasma levels of most metabolites, hormones and lipids. Plasma glucagon and beta-hydroxybutyrate levels, however, became subnormal and the concentration of HDL-cholesterol significantly increased above normal $(p<0.001)$. The latter was mainly due to a more than two-fold increase in the $\mathrm{HDL}_{2}$-cholesterol subfraction resulting in a substantial increase of the $\mathrm{HDL}_{2} / \mathrm{HDL}_{3}$-cholesterol ratio.

The metabolic and endocrine abnormalities at entry of the study were somewhat less striking in children on conventional insulin treatment (Table 3 ) reflecting a lesser degree of metabolic decompensation indicated by their lower $\mathrm{HbA}_{1}$ concentrations (Table 1). Fasting plasma free insulin, glucagon, growth hormone, free fatty acid, beta-hydroxybutyrate, triglyceride, (VLDL + LDL)-cholesterol and $\mathrm{HDL}_{2}$-cholesterol levels were not significantly different from the control subjects, but plasma cholesterol and HDL-cholesterol were elevated due to an increase in $\mathrm{HDL}_{3}$-cholesterol resulting in a low $\mathrm{HDL}_{2} / \mathrm{HDL}_{3}$-cholesterol ratio. The trend of changes following pump treatment was similar to that of Group 1 with a few exceptions. Although the same degree of hypoglucagonaemia developed, there was no further decrease in beta-hydroxybutyrate levels. Furthermore, the fall in total plasma cholesterol levels was not associated with an increase in HDL-cholesterol and $\mathrm{HDL}_{2}$-cholesterol, but a small decrease in the $\mathrm{HDL}_{3}$-cholesterol fraction. This resulted in the normalisation of the $\mathrm{HDL}_{2} / \mathrm{HDL}_{3}$-cholesterol ratio which was significantly lower than normal before pump treatment.

The metabolite and hormonal changes after the ingestion of a test-meal are shown in Figures 1 and 2. The blood glucose curve following a subcutaneous bolus of $0.19 \pm 0.03 \mathrm{U} / \mathrm{kg}$ regular insulin (Novo Actrapid $\mathrm{MC}$ ) and the ingestion of test-meal was almost identical to that of the control subjects in newly-diagnosed diabetic children. In Group 2, a similar bolus of insulin and test-meal were associated with a small increase of blood glucose within the normoglycaemic range (Fig. 1).

The postprandial rise of free insulin level was not statistically different in the control and study groups, but the $1 \mathrm{~h}$-postprandial free insulin concentration tended to be lower in Group 2.

There was a small but significant fall in the mean
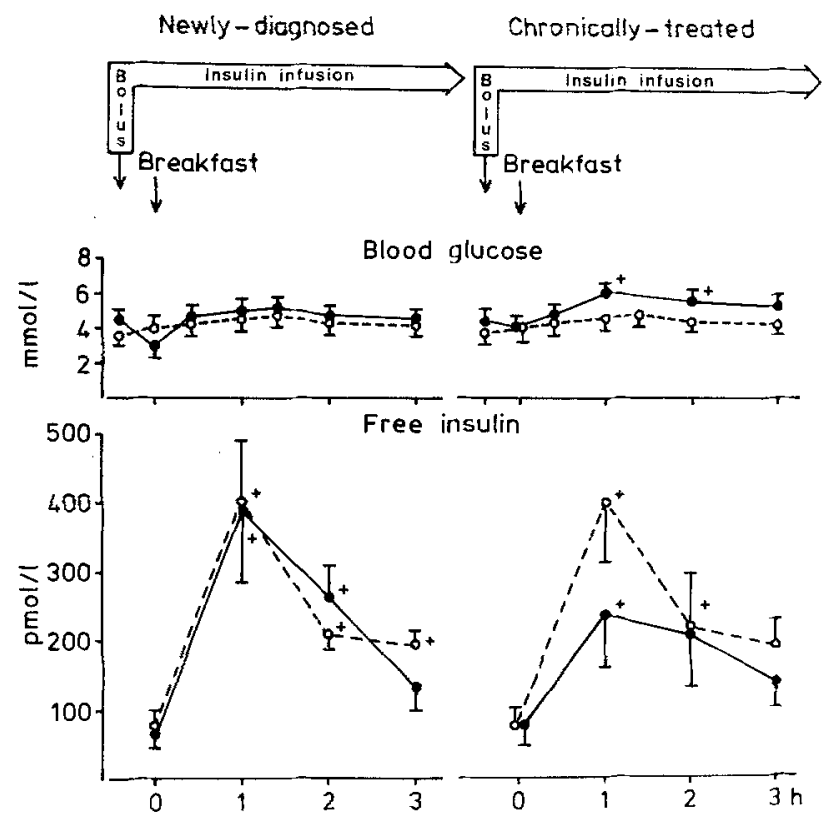

Fig. 1. The effect of insulin and meal on blood glucose and plasma free insulin levels in diabetic children treated with CSII (mean \pm SE) $\bigcirc$ control subjects $(n=9)$, diabetic: Group $1(n=10)$, Group 2 $(n=6),+=p<0.05$ pre - vs postprandial. Solid lines diabetic children dotted lines control subjects
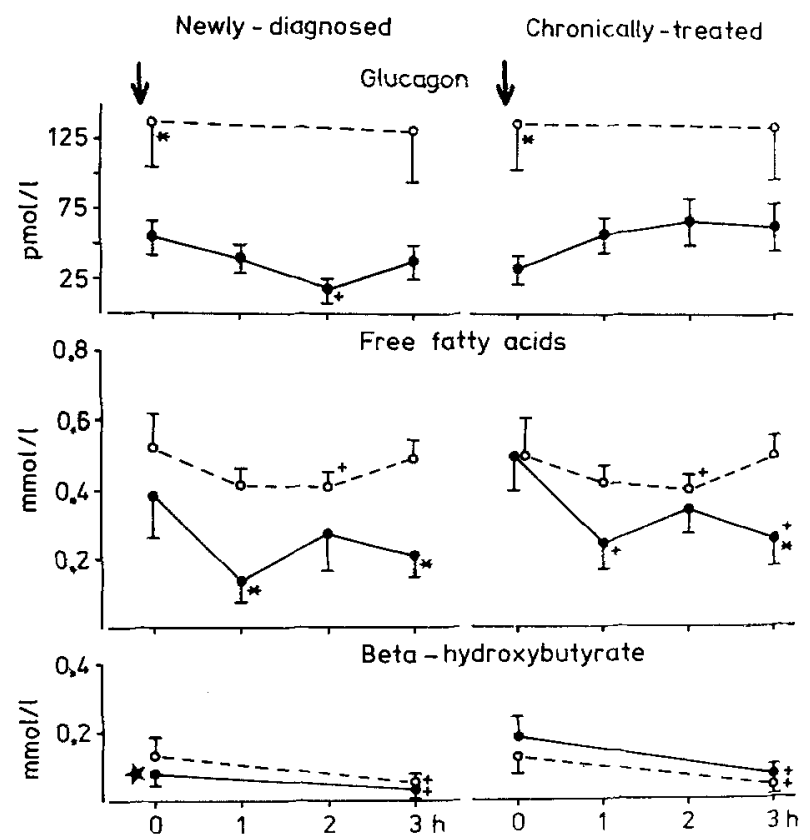

Fig. 2. The effect of insulin and meal on plasma glucagon, free fatty acid and beta-hydroxybutyrate levels in diabetic children treated with CSII (mean \pm SE) O control $(n=9)$, diabetic: Group 1 $(n=10)$, Group $2(n=6),+=p<0.05$ pre- vs postprandial, $\star p<$ 0.01 control subjects vs diabetic children. Solid lines diabetic children, dotted lines control subjects

plasma free fatty acid level at $2 \mathrm{~h}$ postprandially in the control subjects $(p<0.05)$. A similar trend of postprandial decrease was seen in both groups of diabetic children but the fall was significantly greater $(p<0.01)$ (Fig.2). 
Newly-diagnosed

Chronically - treated

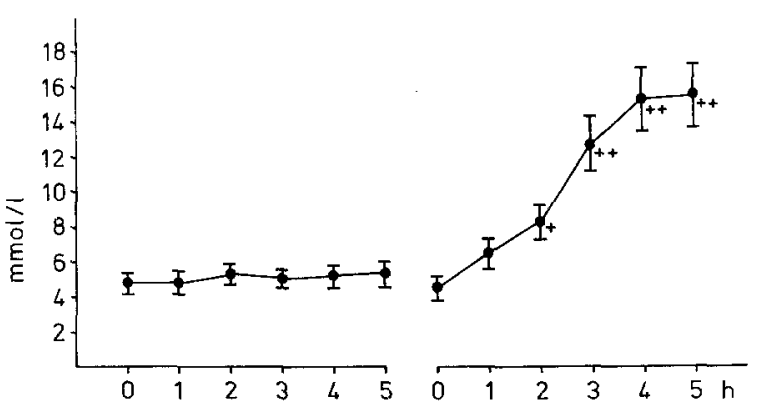

Fig.3. Blood glucose concentration in diabetic children Group 1 $(n=10)$, Group $2(n=6)$ after deliberate disruption of CSII (time 0$)$

As mentioned earlier, both groups of diabetic children had significant fasting hypoglucagonaemia while on pump treatment. Postprandial glucagon levels remained low with a significant further decrease at $2 \mathrm{~h}$ postprandially in Group $1(p<0.05)$ (Fig. 2$)$.

Finally, the postprandial decrease at $3 \mathrm{~h}$ of beta-hydroxybutyrate was similar in all groups. Fasting glucagon, free fatty acid and beta-hydroxybutyrate levels were not related, but there was a significant positive correlation between the postprandial 0 versus $3-\mathrm{h}$ changes of glucagon and free fatty acids $(r=0.713$, $p<0.001)$ and between glucagon and beta-hydroxybutyrate $(r=0.59, p<0.01)$.

Figure 3 demonstrates that newly-diagnosed diabetic children remained normoglycaemic for $5 \mathrm{~h}$ after the interruption of CSII treatment. Their fasting Cpeptide concentration ranged from 0.4 to $1.13 \mathrm{ng} / \mathrm{ml}$. Significant hyperglycaemia developed at 2 to $5 \mathrm{~h}$ following the cessation of subcutaneous insulin infusion in C-peptide negative diabetic children. Ketone bodies, however, could not be detected in the urine of any of these children.

\section{Discussion}

The present study demonstrated that short-term ( 8 to 10 days) CSII treatment resulting in tight control of blood glucose levels (normoglycaemia) is capable of ameliorating the abnormalities in the fasting levels of metabolites, lipids and hormones not only in adult diabetic patients [14-16] but also in diabetic children. The relatively high insulin dose required to achieve normoglycaemia could at least partly be explained by pubertal changes [17]. The effect of pump treatment was particularly striking in newly-diagnosed diabetic children in which the pre-treatment metabolic decompensation was associated with grossly abnormal levels of metabolites, lipids and hormones. In conventionallytreated children, who only had moderate metabolic decompensation at the start of CSII therapy, the magnitude of change was less substantial.

It was particularly interesting to see the effect of CSII on the lipid and lipoprotein abnormalities. In ac- cordance with previous reports in adults and children $[10,18-20]$ we have also shown that short-term intensive insulin treatment in newly-diagnosed diabetic patients resulted in a considerable decrease in plasma (VLDL + LDL)-cholesterol and an increase in HDLcholesterol levels. The demonstration, that the latter was mainly due to a more than two-fold increase in the level of the $\mathrm{HDL}_{2}$-cholesterol subfraction has not been reported previously in children. Upon entry to the study, conventionally treated diabetic children also had higher mean plasma cholesterol level than the control subjects but this was mainly due to the elevated HDLcholesterol and $\mathrm{HDL}_{3}$-cholesterol levels. The increase in HDL-cholesterol after insulin treatment is well documented [18-20] but the elevated HDL-cholesterol level is mainly due to the increase of the $\mathrm{HDL}_{2}$ subfraction [18]. We cannot offer any apparent explanation for the increased $\mathrm{HDL}_{3}$-cholesterol and normal $\mathrm{HDL}_{2}$ cholesterol levels in Group 2. It was also surprising to observe that although pump treatment resulted in the normalisation of the $\mathrm{HDL}_{2} / \mathrm{HDL}_{3}$-cholesterol ratio, this was mainly due to a decrease in the level of $\mathrm{HDL}_{3}$-cholesterol rather than to an increase in the concentration of $\mathrm{HDL}_{2}$-cholesterol. The HDL-cholesterol subfractions, $\mathrm{HDL}_{3}$ - and $\mathrm{HDL}_{3}$-cholesterol, measured in this study by the precipitation technique, are generated by lipoprotein lipase, which degrades triglyceriderich lipoproteins and tranfers surface material to HDL, converting $\mathrm{HDL}_{3}$ to $\mathrm{HDL}_{2}$ [21-22]. $\mathrm{HDL}_{2}$-cholesterol is the more variable component and it is regarded to be a more meaningful index of altered HDL-metabolism.

Furthermore, the study of metabolites and hormones following ingestion of a test-meal has shown that CSII with meal-time bolus superimposed on a fixed basal rate results in a more physiological insulin and metabolite profile with provision of a rapid increase in plasma insulin levels synchronized with nutrient absorption.

The data have also shown, however, that the metabolic and endocrine milieu produced by CSII is not entirely physiological. Both groups of diabetic children developed fasting hypoglucagonaemia on CSII and fasting beta-hydroxybutyrate levels dropped below normal in Group 1. These changes together with the "abnormal" postprandial fall in glucagon and free fatty acid levels suggest increased insulin action. Glucagon was particularly suppressed in newly-diagnosed diabetic children whose fasting insulin concentration also tended to be higher as compared to children in Group 2 (Table 3). In other words, the restoration of normoglycaemia and the normalisation of the multiple metabolic abnormalities appear to be possible only by "hyperinsulinisation" as indirectly suggested by the above mentioned changes. Both fasting free insulin levels and the postprandial increase in free insulin concentration, however, were comparable to normal subjects. This, in agreement with previous reports in adult patients $[16,23]$ does not exclude the possibility of in- 
creased insulin action as indirectly suggested by the metabolite changes. There are at least two possible explanations for the apparently increased insulin action despite the failure to detect differences in peripheral insulin levels. The first possibility is a difference in insulin sensitivity which could lead to an enhanced in vivo insulin effect during CSII as demonstrated by BeckNielsen et al. [24]. Secondly, it is also possible that the current methodology for free insulin determination may not be sensitive enough to detect small changes in ambient free insulin levels [23].

Since diabetic children in general are ketosis-prone, and exercise, feeding and the stress of infection may exacerbate metabolic decompensation in pump patients who are already at risk because of the small subcutaneous reservoir of insulin during CSII, the safety of this therapy is of paramount importance. Our study has shown that patients must be alert to this potential danger: although ketosis did not develop during the $5 \mathrm{~h}$ of insulin lack, blood glucose levels considerably increased in C-peptide negative diabetic children. Pickup [25] has observed a significant increase in plasma beta-hydroxybutyrate and potassium levels only after 4 to $6 \mathrm{~h}$ of interruption of CSII in C-peptide negative adult diabetic patients.

In summary, short-term CSII therapy in children may lead to improved glycaemic control and to the restoration of multiple metabolic abnormalities including favourable changes in the atherosclerosis-protective lipoproteins without providing an entirely physiological metabolic and endocrine milieu.

\section{References}

1. Riley WJ, Silverstein JK, Rosenbloom AL, Spillar R, McCallum MH (1980) Ambulatory diabetes management with pulsed subcutaneous insulin using a portable pump. Clin Pediatr 19: 609-614

2. Greene SA, Smith MA, Baum JD (1983) Clinical application of insulin pumps in the management of insulin dependent diabetes. Arch Dis Child 58: 578-581

3. Chiumello G, Beccaria $L$, diNatale B, d'Arcais F, Mariani $R$, Meschi F, Pedone A, Somaschini M (1983) Stable $\mathrm{Hb}_{\mathrm{A} 1}$, C-peptide secretion, and insulin binding after continuous subcutaneous insulin infusion in diabetic children at onset. In: Chiumello G, Sperling M (eds) Recent Progress in Pediatric Endocrinology. Raven Press, New York, pp 141-147

4. Davies AG, Price DA, Houlton CA, Burn JL, Fielding BA, Postlethwaite RJ (1984) Continuous subcutaneous insulin infusion in diabetes mellitus. Arch Dis Child 59: 1027-1033

5. Braham D, Tinder P (1972) An improved reagent for the determination of blood glucose by the oxidase system. Analyst 97: 142-145

6. Laurell S, Tibbling G (1967) Colorimetric microdetermination of free fatty acids in plasma. Clin Chim Acta 16: 57-62

7. Bergmeyer HU (1974) Methods of enzymatic analysis, vols 1-4, 2nd English edn. Verlag Chemie, Weinheim; Academic Press, New York San Francisco London

8. Steele BW, Rochler DF, Azar MM, Blászkowski TB, Ruba K, Dempsey ME (1976) Enzymatic determination of cholesterol in high-density lipoprotein fractions prepared by a precipitation technique. Clin Chem 22: 98-102
9. Khan SR, Elkeles RS, Nithyananthan R, Seed M, Wynn V (1982) Analysis of high density lipoprotein subclasses by a precipitation procedure: comparison with preparative ultracentrifuge. Clin Chim Acta 120: 49-54

10. Klujber L, Molnár D, Kardos M, Jászai V, Soltész G, Mestyán J (1979) Metabolic control, glycosylated haemoglobin and high density lipoprotein cholesterol in diabetic children. Eur $\mathbf{J}$ Pediatr 132: $289-297$

11. Nakagawa S, Nakagama H, Sasaki T, Yoshino K, Yu YY, Shinozaki K, Aoki S, Mashimo K (1973) A simple method for the determination of serum free insulin levels in insulin-treated patients. Diabetes 22: 590-600

12. Brook CGD (1971) Determination of body composition of children from skinfold measurements. Arch Dis Child 46: 182-186

13. Durnin JVGA, Rahaman MM (1967) The assessment of the amount of fat in the human body from measurements of skinfold thickness. Br J Nutr 21: 681-688

14. Pickup JC, Keen $\mathrm{H}$, Parsons JA, Alberti KGMM, Rowe AS (1979) Continuous subcutaneous insulin infusion: improved blood glucose and intermediary-metabolite control in diabetics. Lancet I: $1255-1258$

15. Tamborlane WV, Sherwin RS, Genel M, Felig P (1979) Restoration of normal lipid and amino-acid metabolism in diabetic patients treated with a portable insulin-infusion pump. Lancet I: 1258-1261

16. Hermansen K, Moller A, Christensen CK, Cristiansen JS, Schmitz O, Orskov H, Alberti KGMM, Morgensen CE (1987) Diurnal plasma profiles of metabolite and hormone concentration in insulin-dependent diabetic patients during conventional insulin treatment and continuous subcutaneous insulin infusion. A controlled study. Acta Endocrinol (Copenh) 114: 433-439

17. Mann NP, Johnston DI (1984) Improvement in metabolic control in diabetic adolescents by the use of increased insulin dose. Diabetes Care 7: 460-464

18. Nikkilä EA (1981) High density lipoproteins in diabetes. Diabetes 30 [Suppl 2]: 82-87

19. Lopes-Virella MF, Wohltmann HJ, Mayfield RK, Loadholt CB, Colwell JA (1983) Effect of metabolic control on lipid, lipoprotein, and apolipoprotein levels in 55 insulin-dependent diabetic patients. A longitudinal study. Diabetes 32: 20-25

20. Ewald U, Gustafson S, Tuvemo T, Vessby B (1984) Increased high density lipoproteins in diabetic children. Eur J Pediatr 142: 154-156

21. Patsch JR, Gotto AM, Olivecrona T, Eisenberg S (1978) Formation of high density lipoprotein-like particles during lipolysis of very low density lipoproteins in vitro. Proc Natl Acad Sci USA 75: 4519-4523

22. Gidez LJ, Miller GJ, Burstein M, Slagle S, Eder HA (1982) Separation and quantitation of subclasses of human plasma high density lipoproteins by a simple precipitation procedure. J Lipid Res 23: 1206-1223

23. Koivisto VA, Yki-Järvinen $H$, Helve E, Karonen S-L, Pelkonen $R$ (1986) Pathogenesis and prevention of dawn phenomenon in diabetic patients treated with CSII. Diabetes 35:78-82

24. Beck-Nielsen $H$, Richelsen B, Hasling C, Hother Nielsen $O$, Heding L, Sorensen NS (1984) Improved in vivo insulin effect during continuous subcutaneous insulin infusion in patients with IDDM. Diabetes 33: 832-836

25. Pickup JD (1986) Hyperkalaemia after interruption of CSII. Diabetologia 29: $823-824$

Received: 11 August 1987

and in revised form: 25 November 1987

Dr. G. Soltész

Department of Paediatrics

University of Pécs

H-7623 Pécs

Hungary 